Biological and Clinical Sciences Research Journal

ISSN: 2708-2261

www.bcsrj.com

DOI: https://doi.org/10.54112/bcsrj.v2020i1.43

Biol. Clin. Sci. Res. J., Volume, 2020: 43

Original Research

\title{
PREDICTIVE ACCURACY OF CERVICAL LENGTH IN MID TRIMESTER ON TRANSABDOMINAL ULTRASOUND FOR CESAREAN SECTION
}

\author{
KHALID A ${ }^{1}$, ANJUM MN ${ }^{1}$, DARAAZ $\mathbf{U}^{1}$, HUSSAIN K ${ }^{2}$, OMER MA ${ }^{3 *}$ \\ ${ }^{I}$ Department of Diagnostic Radiology, The University of Lahore, Lahore, Pakistan \\ ${ }^{2}$ Social security hospital Kasur, Pakistan \\ ${ }^{3}$ Department of Radiology, DHQ Hospital Sheikupura, Pakistan \\ Corresponding author email: dr.arslan14@gmail.com
}

(Received, $5^{\text {th }}$ July 2020, Revised $30^{\text {th }}$ November 2020, Published $2^{\text {nd }}$ December 2020)

\begin{abstract}
The Cesarean section (CS) delivery is a most frequent surgical technique worldwide. The CS increasing rate and its related problems have drawn an attention towards CS related morbidity. As recommended by WHO, Csection could be carried out only when required medically. In mid-pregnancy cervical extended length predicts the probability of CS early in the pregnancy. The objective of the study is to find the predictive accuracy of cervical length $(C L)$ on transabdominal ultrasound for cesarean section in mid trimester taking mode of delivery as gold standard. It was a cross sectional study in which 362 females were enrolled. Females were undergoing transabdominal ultrasonography for assessment of cervical length. A $2 \times 2$ contingency table was generated to calculate sensitivity, specificity, positive predictive valve (PPV), negative predictive value (NPV) and diagnostic accuracy of transabdominal ultrasound taking actual mode of delivery as gold standard. The mean age of the females was $27.92+5.75$ years while mean parity and mean $C L$ were $2.22+1.30$ and $35.83+7.96 \mathrm{~mm}$, respectively. Among 30 females who had cervical length $<25 \mathrm{~mm}, 24$ had CS and 6 had spontaneous vaginal delivery (SVD). Among 332 females who had cervical length >25 mm, 96 had CS and 236 had SVD. The sensitivity, specificity, PPV, NPV and diagnostic accuracy of transabdominal ultrasound for cesarean section were 20.0\%, $97.5 \%, 80.0 \%, 71.1 \%$ and $71.8 \%$, respectively. Study concluded that cesarean section takes place among pregnant females when cervical length is $\leq 25 \mathrm{~mm}$ on transabdominal ultrasound during mid trimester.
\end{abstract}

Keywords: Predictive accuracy, cervical length, mid trimester, transabdominal ultrasound, cesarean section

\section{Introduction}

"Once a cesarean, always a cesarean" was rule for the traditional CS (cesarean section) however, currently cesarean section is believed a secure delivery mode related to less perinatal difficulties regardless of elevated health and pecuniary cost (Ehtisham and Hashmi, 2014). The CS delivery is a most frequent surgical technique worldwide for females during childbearing age (Anjum et al., 2020) with 18.5 million estimated cases carried out yearly (Stark et al., 2017). Among both developed and industrialized countries, cesarean section is believed an ideal technique for childbirth (Verma et al., 2020). The CS increasing rate and its related problems have drawn an attention towards CS scars as well as their possible related morbidity (Naji et al., 2012). A CS delivery could be conducted based on mother's pelvis shape or CS previous history. After cesarean section, vaginal birth trial could be possible. As recommended by WHO, C-section could be carried out only when required medically. Several cesarean deliveries are conducted without any medical cause, on someone request, mostly the mother (Caughey et al., 2014). Generally, the cesarean sections lead to a little rise in the poor outcomes among low-risk pregnancies. Also, they normally require longer time to heal, almost 6 weeks (Caughey et al., 2014), than the vaginal delivery. The enhanced risks comprise breathing difficulties in child and postpartum hemorrhage \& amniotic fluid embolism in mother. Traditional guidelines propose that CSs not be utilized prior to pregnancy 39 weeks with no any medical cause. The delivery technique does not affect the sexual function afterward (Yeniel and Petri, 2014).

The shortening of cervix is an initial step during processes causing labor and may precede the labor by numerous weeks. During 2nd trimester a reduction in the cervical length $(\mathrm{CL})$ is predictive of impulsive

[Citation: Khalid, A., Anjum, M.N., Daraaz, U., Hassan, K., Omer, M.A. (2020). Predictive accuracy of cervical length in mid trimester on transabdominal ultrasound for cesarean section. Biol. Clin. Sci. Res. J., 2020: 43. doi: https://doi.org/10.54112/bcsrj.v2020i1.43] 
preterm delivery, with an elevated risk among females with untimely and significant cervical shortening. As effacement starts at internal cervical os and grows backwardly, it is mostly identified on ultrasound (US) evaluation before it could be valued upon physical examination (Romero et al., 2016; Valentin, 2013). Females who experienced CS were 27.5 percent while 33.1 percent delivered babies normally those identified for cervical length during 2nd trimester (Gameraddin, 2018). Measurement of cervical length utilizing transvaginal ultrasound is a crucial part of evaluating the chance of preterm birth. It is a helpful technique at mid gestation to forecast the possibility of later preterm delivery in asymptomatic females (Kagan and Sonek, 2015).

However, CL is believed as forecaster regarding mode and timing of the delivery, this is not utilized like a screening instrument in asymptomatic low risk populace (Thangaraj et al., 2018). Transabdominal ultrasound is most frequently utilized to attain images of urogenital, hepatobiliary \& pelvic structures. Its usefulness regarding imaging the alimentary GIT (gastrointestinal tract) is not well recognized, principally due to technical problems in getting quality images for these areas. Though, advancements in US technology and growing knowledge with US findings in various gastrointestinal complaints are expanding its applications (Nylund et al., 2017). At vaginal assessment, cervix digital evaluation is biased and is unsurprisingly subject to significant bias (Pomorski et al., 2016). Hence, the cervical length measurement on ultrasound is apparently more appealing alternative to forecast the success of labour induction (Hatfield et al., 2007). In mid-pregnancy cervical extended length predicts the probability of CS early in the pregnancy. Therefore, during midpregnancy cervical length can be significant to predict the delivery mode during early pregnancy (Kalu et al., 2012). It was reported the transabdominal ultrasonography sensitivity and specificity as an investigation to identify the cervical length upto $25 \mathrm{~mm}$ were 10 percent and 94 percent, respectively, to predict CS as delivery mode (Westerway et al., 2015). Current study is carried out to get the evidence regarding accuracy of transabdominal ultrasound for prediction of mode of delivery using cervical length in second trimester and plan the mode of delivery and prepare the patients for particular mode of delivery on the basis of cervical length assessment on transabdominal ultrasound. This would help health care providers to improve their practice and will also add information to already existing literature.

\section{Material and methods}

It was a cross sectional study in which 362 females were enrolled. Females were undergoing transabdominal ultrasonography for assessment of cervical length by researcher and findings were recorded. Females were labeled as positive or negative and all females were booked and followed-up in OPD by obstetrician. At time of delivery, mode of delivery was noted as decided by obstetrician. Data was entered and statistically analyzed using SPSS 21.0. Quantitative variables were described as mean and SD. Qualitative variables were described as frequency and percentage. A $2 \times 2$ contingency table was generated to calculate sensitivity, specificity, PPV, NPV and diagnostic accuracy of transabdominal ultrasound taking actual mode of delivery as gold standard.

\section{Results}

Table-1 describes that among 362 females, 140 $(38.7 \%)$ were up to 25 years old and most of them 180 (49.6\%) were $26-35$ years old while only 42 (11.7\%) females were more than 35 years old. The mean age of the females was $27.92 \pm 5.75$ years. Table 1a indicates that among 362 females, $22(6.1 \%)$ had no parity while $194(53.5 \%)$ and $146(40.4 \%)$ females had given birth to 1-2 and 3-5 children, respectively. The mean parity among females was $2.22+1.30$. Table 2 shows that out of 362 females, only 30 (8.3\%) had cervical length $<25 \mathrm{~mm}$ while major proportion $332(91.7 \%)$ of females had cervical length $>25 \mathrm{~mm}$. The mean cervical length was $35.83+7.96 \mathrm{~mm}$. Table-3 highlights that among 362 females, 120 (33.1\%) experienced cesarean section while for majority $242(66.9 \%)$ the mode of delivery was SVD (spontaneous vaginal delivery). Table-4 exhibits that among 30 females who had cervical length $<25 \mathrm{~mm}$, $24(6.6 \%)$ had cesarean section and $6(1.7 \%)$ had SVD. Among 332 females who had cervical length $>25 \mathrm{~mm}, 96(26.5 \%)$ had cesarean section and 236 (65.5\%) had SVD. The sensitivity, specificity, PPV, NPV and diagnostic accuracy of transabdominal ultrasound for cesarean section were $20.0 \%$, 97.5\%, $80.0 \%, 71.1 \%$ and $71.8 \%$, respectively.

Table 1. Frequency distribution of females according to age

\begin{tabular}{lcc}
\hline \multicolumn{1}{c}{ Age } & Frequency & Percentage $(\boldsymbol{\%})$ \\
\hline Upto 25 years & 140 & 38.7 \\
26-35 years & 180 & 49.6 \\
Above 35 years & 42 & 11.7 \\
Total & 362 & 100.0 \\
Mean + SD & \multicolumn{2}{c}{$27.92+5.75$} \\
\hline
\end{tabular}

Table 1a: Frequency distribution of females according to parity

[Citation: Khalid, A., Anjum, M.N., Daraaz, U., Hassan, K., Omer, M.A. (2020). Predictive accuracy of cervical length in mid trimester on transabdominal ultrasound for cesarean section. Biol. Clin. Sci. Res. J., 2020: 43. doi: https://doi.org/10.54112/bcsrj.v2020i1.43] 


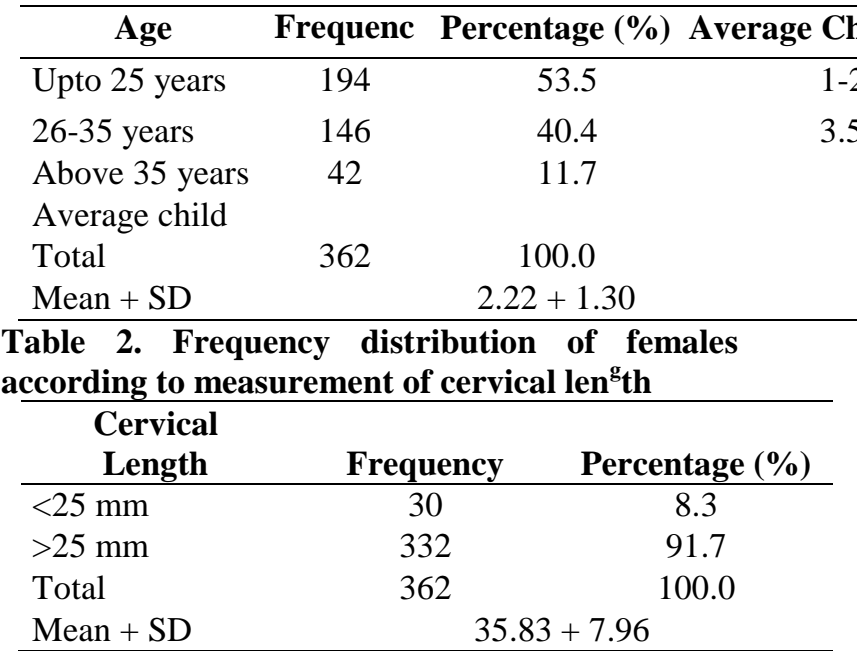

Table 3. Frequency distribution of females according to mode of delivery

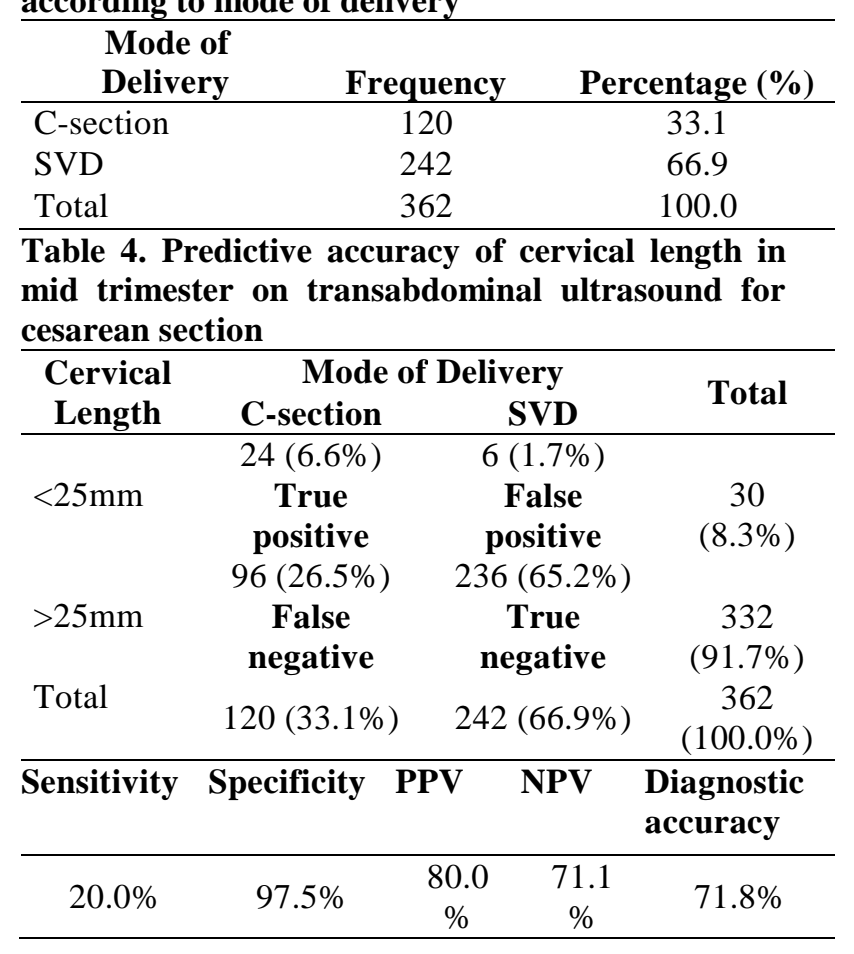

\section{Discussion}

Current study was undertaken to assess the predictive accuracy of cervical length in mid trimester on transabdominal ultrasound for cesarean section at Department of Radiology, University of Lahore, Raiwind Road, Lahore. To acquire adequate outcomes, a group of 362 females was included in the study. Study revealed that most of the females were in their good reproductive age group as $88.3 \%$ were up to 35 years old and only $11.7 \%$ females were more than 35 years old. The
Childean age of the females was $27.92+5.75$ years. 1-2 The findings of our study are comparable with a 3.5 study carried out by Gameraddin and Bashab who .5 reported that major proportion $(75.5 \%)$ of females was up to 35 years old $24.5 \%$ females were more than 35 years old (Gameraddin and Bashab, 2018). 10 The findings of another study conducted by Nambiar and his fellows also demonstrated similar scenario that mean age of the pregnant females was 27.27 \pm 4.87 years (Nambiar et al., 2017). It was found during study that only $6.1 \%$ females had no parity while more than half $(53.5 \%)$ of the females delivered 1-2 children and $40.4 \%$ females delivered $3-5$ children. The mean parity was $2.22+1.30$. Nambiar and fellows reported in their study that majority of females $(77.2 \%)$ gave birth to one child while 22.8 females gave birth to more than one child (Nambiar et al., 2017). Another recent study conducted by Peng and his colleagues indicated that more than half $(55.4 \%)$ of the females 19 nulliparous while $44.6 \%$ were multiparous (Peng et al., 2015). Cervical length is believed as important predictor in pregnant females to assess the mode and timing of the delivery. It is believed that when cervical length $<25$ is $\mathrm{mm}$ then there is great chance of cesarean section delivery. It is significant to mention here that only $8.3 \%$ females have cervical length up to $25 \mathrm{~mm}$ while significant major (91.7\%) had cervical length above $25 \mathrm{~mm}$. The mean cervical length was $35.83+7.96 \mathrm{~mm}$. The findings of study undertaken by HernandezAndrade and his coworker showed almost similar results that mean cervical length was $34.6+7.55$ $\mathrm{mm}$ (Hernandez-Andrade et al., 2012). But the results of a study carried out by Gameraddin and Bashab exhibited different scenario that mean cervical length was $38.20 \pm 5.20 \mathrm{~mm}$ (Gameraddin and Bashab, 2018) The findings of another study conducted by Buathum a comrades (2019) also confirmed that mean cervical length was $39.3+6.4$ $\mathrm{mm}$. As far as mode of delivery is concerned, study highlights that among $33.1 \%$ females the mode of delivery $\mathrm{w}$ cesarean section while among majority (66.9\%) the mo of delivery was SVD (spontaneous vaginal delivery). The findings of a similar study carried out by Rane and his associates exhibited better scenario than our study results who confirmed that only $18.9 \%$ female experienced cesarean section while mainstream $(81.1 \%)$ females had vaginal delivery (Rane et al., 2003). Also the results of another study performed by Gameraddin and Bashab are better than our study results who stated that $27.5 \%$ females experience cesarean delivery (Gameraddin and Bashab, 2018). When

[Citation: Khalid, A., Anjum, M.N., Daraaz, U., Hassan, K., Omer, M.A. (2020). Predictive accuracy of cervical length in mid trimester on transabdominal ultrasound for cesarean section. Biol. Clin. Sci. Res. J., 2020: 43. doi: https://doi.org/10.54112/bcsrj.v2020i1.43] 
the cervical length and mode of delivery was assessed, study indicated that among 30 females who has cervical lengths $<25 \mathrm{~mm}, 24$ (true positive) experienced C-section and only 6 (false positive) had spontaneous vagina delivery. Likewise, among 332 females who had cervical length $>25 \mathrm{~mm}, 96$ (false negative) had cesarean section and 236 (true negative) had SVD. The sensitivity specificity, PPV, NPV and diagnostic accuracy transabdominal ultrasound for cesarean section we $20.0 \%, 97.5 \%$, $80.0 \%, 71.1 \%$ and $71.8 \%$, respectively was reported in a recent study carried out by El Mekka and his collaborators reported that CL $<28 \mathrm{~mm}$ had sensivity $87.5 \%$, specificity $86.3 \%$, PPV $61.4 \%$, and NPV $96.5 \%$ the induction of successful labor (El Mekkawi et al., 2019). In a study, Saul and his colleagues found 100 percent sensitivity of transabdominal ultrasonography for cervical length assessment upto $25 \mathrm{~mm}$ (Saul et al., 2008). Westerway and his colleagues reported that transabdominal ultrasonography sensitivity a specificity to identify the cervical length upto $25 \mathrm{~mm}$ was 10 percent and 94 percent, respectively, to predict CS delivery mode (Westerway et al., 2015).

\section{Conclusion}

Study concluded that cesarean section takes place among pregnant females when cervical length is $\leq 25 \mathrm{~mm}$ on transabdominal ultrasound during mid trimester.

\section{Reference}

Anjum, N., Memon, Z., Sheikh, S., and Naz, U. (2020). Relationship between cervical dilatation at which women present in labor and subsequent rate of caesarian section. Journal of Ayub Medical College Abbottabad 32, 5863.

Caughey, A. B., Cahill, A. G., Guise, J.-M., Rouse, D. J., Obstetricians, A. C. o., and Gynecologists (2014). Safe prevention of the primary cesarean delivery. American journal of obstetrics and gynecology 210, 179-193.

Ehtisham, S., and Hashmi, H. A. (2014). Determinants of caesarean section in a tertiary hospital. Parity 2, 3.65.

El Mekkawi, S., Hanafi, S., Khalaf-Allah, A., Abdelazim, I. A., and Mohammed, E. (2019). Comparison of transvaginal cervical length and modified Bishop's score as predictors for labor induction in nulliparous women. Asian Pacific Journal of Reproduction 8, 34.

Gameraddin, M. (2018). Ultrasound evaluation of cervical length in the second trimester of pregnancy: The impact of cesarean section and ethnicity. Journal of Current Research in Scientific Medicine 4, 17.

Gameraddin, M. B., and Bashab, N. K. (2018). Characterisation of Benign Ovarian Lesions among Sudanese Women Undergoing Pelvic Ultrasound Scans: The Impact of Parity and Age. Journal of Clinical \& Diagnostic Research 12.

Hatfield, A. S., Sanchez-Ramos, L., and Kaunitz, A. M. (2007). Sonographic cervical assessment to predict the success of labor induction: a systematic review with metaanalysis. American journal of obstetrics and gynecology 197, 186-192.

Hernandez-Andrade, E., Romero, R., Ahn, H., Hussein, Y., Yeo, L., Korzeniewski, S. J., Chaiworapongsa, T., and Hassan, S. S. (2012). Transabdominal evaluation of uterine cervical length during pregnancy fails to identify a substantial number of women with a short cervix. The Journal of Maternal-Fetal \& Neonatal Medicine 25, 1682-1689.

Kagan, K., and Sonek, J. (2015). How to measure cervical length. Ultrasound in Obstetrics \& Gynecology 45, 358-362.

Kalu, C. A., Umeora, O., Egwuatu, E., and Okwor, A. (2012). Predicting mode of delivery using mid-pregnancy ultrasonographic measurement of cervical length. Nigerian journal of clinical practice 15, 338-343.

Naji, O., Abdallah, Y., Bij De Vaate, A., Smith, A., Pexsters, A., Stalder, C., McIndoe, A., Ghaem-Maghami, S., Lees, C., and Brölmann, H. (2012). Standardized approach for imaging and measuring Cesarean section scars using ultrasonography. Ultrasound in obstetrics \& gynecology 39, 252-259.

Nambiar, J. M., Pai, M. V., Reddy, A., and Kumar, P. (2017). Can transabdominal scan predict a short cervix by transvaginal scan? Obstetrics and gynecology international 2017.

Nylund, K., Maconi, G., Hollerweger, A., Ripolles, T., Pallotta, N., Higginson, A., Serra, C., Dietrich, C., Sporea, I., and Saftoiu, A. (2017). EFSUMB recommendations and guidelines for gastrointestinal ultrasound.

Peng, C.-R., Chen, C.-P., Wang, K.-G., Wang, L.-K., Chen, C.-Y., and Chen, Y.-Y. (2015). The reliability of transabdominal cervical length measurement in a low-risk obstetric population: Comparison with transvaginal measurement. Taiwanese Journal of Obstetrics and Gynecology 54, 167-171.

[Citation: Khalid, A., Anjum, M.N., Daraaz, U., Hassan, K., Omer, M.A. (2020). Predictive accuracy of cervical length in mid trimester on transabdominal ultrasound for cesarean section. Biol. Clin. Sci. Res. J., 2020: 43. doi: https://doi.org/10.54112/bcsrj.v2020i1.43] 
Pomorski, M., Fuchs, T., Rosner-Tenerowicz, A., and Zimmer, M. (2016). Standardized ultrasonographic approach for the assessment of risk factors of incomplete healing of the cesarean section scar in the uterus. European Journal of Obstetrics \& Gynecology and Reproductive Biology 205, 141-145.

Rane, S., Guirgis, R., Higgins, B., and Nicolaides, K. (2003). Pre-induction sonographic measurement of cervical length in prolonged pregnancy: the effect of parity in the prediction of the need for Cesarean section. Ultrasound in Obstetrics and Gynecology: The Official Journal of the International Society of Ultrasound in Obstetrics and Gynecology 22, 45-48.

Romero, R., Nicolaides, K., Conde-Agudelo, A., O'brien, J., Cetingoz, E., Da Fonseca, E., Creasy, G., and Hassan, S. (2016). Vaginal progesterone decreases preterm birth $\leq 34$ weeks of gestation in women with a singleton pregnancy and a short cervix: an updated meta-analysis including data from the OPPTIMUM study. Ultrasound in Obstetrics \& Gynecology 48, 308-317.

Saul, L. L., Kurtzman, J. T., Hagemann, C., Ghamsary, M., and Wing, D. A. (2008). Is transabdominal sonography of the cervix after voiding a reliable method of cervical length assessment? Journal of Ultrasound in Medicine 27, 1305-1311.

Stark, M., Odent, M., Tinelli, A., Malvasi, A., and Jauniaux, E. (2017). Cesarean Section: The Evidence-Based Technique, Complications, and Risks. In "Management and Therapy of Late Pregnancy Complications", pp. 209-231. Springer.

Thangaraj, J. S., Habeebullah, S., Samal, S. K., and Amal, S. S. (2018). Mid-pregnancy ultrasonographic cervical length measurement (A predictor of mode and timing of delivery): an observational study. Journal of family \& reproductive health $\mathbf{1 2}, 23$.

Valentin, L. (2013). Prediction of scar integrity and vaginal birth after caesarean delivery. Best practice \& research Clinical obstetrics \& gynaecology 27, 285-295.

Verma, V., Vishwakarma, R. K., Nath, D. C., Khan, H. T., Prakash, R., and Abid, O. (2020). Prevalence and determinants of caesarean section in South and South-East Asian women. Plos one 15, e0229906.

Westerway, S. C., Pedersen, L. H., and Hyett, J. (2015). Cervical length measurement: comparison of transabdominal and transvaginal approach. Australasian Journal of Ultrasound in Medicine 18, 19-26.

Yeniel, A., and Petri, E. (2014). Pregnancy, childbirth, and sexual function: perceptions and facts. International urogynecology journal 25, 5-14.

\section{(cc) (7) \&}

Open Access This article is licensed under a Creative Commons Attribution 4.0 International License, which permits use, sharing, adaptation, distribution and reproduction in any medium or format, as long as you give appropriate credit to the original author(s) and the source, provide a link to the Creative Commons licence, and indicate if changes were made. The images or other third party material in this article are included in the article's Creative Commons licence, unless indicated otherwise in a credit line to the material. If material is not included in the article's Creative Commons licence and your intended use is not permitted by statutory regulation or exceeds the permitted use, you will need to obtain permission directly from the copyright holder. To view a copy of this licence, visit http://creativecommons.org/licen ses/by/4.0/.

(C) The Author(s) 2020

[Citation: Khalid, A., Anjum, M.N., Daraaz, U., Hassan, K., Omer, M.A. (2020). Predictive accuracy of cervical length in mid trimester on transabdominal ultrasound for cesarean section. Biol. Clin. Sci. Res. J., 2020: 43. doi: https://doi.org/10.54112/bcsrj.v2020i1.43] 